\title{
Examining the dynamics of novation from the principal contractor's and architect's perspectives
}

Alan Griffith, Andrew King (Centre for the Built Environment, School of Environment and Development,

Sheffield Hallam University, UK) and Andrew Knight (School of Property and Construction, Nottingham Trent University, UK)

\section{ABSTRACT}

Design and build is a popular form of procurement worldwide. In its conventional form, it is characterised by the integration between design and construction. Novation, a variant of design and build where design responsibility is transferred from designer to contractor as procurement evolves, has gained in popularity. However, the characteristics of the process, although well identified, continue to create confusion and problems for clients and contractors alike. This paper focuses on the dynamics of design and build novation from the principal contractor's and architect's perspectives. It embraces key aspects of both the pre-contract and post-contract environment. Its contribution forms a part of a major UK Government funded research project investigating design and build best practice. The findings presented in this paper broadly indicate that contractors believe novated design and build can be disadvantageous and that considerable fragmentation can be created in what should be an integrated procurement approach.

Keywords - construction, procurement, design and build, novation, tendering

\section{INTRODUCTION}

\section{Design and build}

Design and build is a popular form of procurement adopted in many countries. Characterised by its design-construction integration, guaranteed price, short on-site construction phase and single point responsibility, it apportions responsibility for the end product clearly to the principal contractor. The need to move towards more closely integrated procurement has been discussed for many years and is founded in the problems with traditional procurement; poor relationships between contractual parties, project overrun, cost uncertainty, contested claims and litigious actions (Banwell, 1964; Turner, A., 1990; Latham, 1994; Turner, D.F., 1995).

Responsibility for design and construction being assumed by one contractual party is understandably limited for two principal reasons. First, clients want project development advice from an impartial source. Second, clients seek the preparation of project development information which facilitates competitive tendering. Depending on the type of design and build, the client may employ consultants to develop the project brief, outline drawings and specification for the works. This activity constitutes the employer's requirements and is the only document that the client needs to produce. The principal contractor then develops his tender based on these requirements and collates the tender package into a Contractor's Proposal document. The client, typically with the aid of his consultants, selects the contractor based upon the proposal submitted.

\section{Novation}

Novation is one derivative of design and build that can be considered a legal 'bolt on'. It has been described as 'an arranged marriage' (Schuman, 1999) and its principal defining feature is that once the initial project requirements have been prepared by the client's consultants and the principal contractor selected, the contractor then employs the client's consultant to complete the post-contract design stage. It should be noted that novation can apply to different types of designers and consultants, for example, architects and structural and mechanical engineers. This research study is principally concerned with the most common type in the UK; architect novation.

Novation has over the years been confused with the concept of consultant switch. Chappell (1994) differentiates the two; novation rescinds the original contract between the client and consultant, and replaces it with a new one between contractor and designer, thereby clarifying loyalties. Whereas consultant switch, it seems, may result in the designer still being contractually bound to the client at the same time as he is to the contractor, leading to the problems of unclear liabilities. The usage of both these terms does seem to be prevalent in literature, for example Andrews (1999), and may be responsible for a certain amount of confusion (Chevin, 1993).

Siddiqui's 1996 study of novation appears to conceptualise novation in a different way to design and build. It would seem that Siddiqui perceives design and build as a static concept, which refers to the total provision of design and construction by one party: the construction contractor. However, a more useful understanding is to consider design and build as a family of procurement options characterised by their integrated approach. This conceptualisation allows the many hybrids of design and build to be included which differ principally around the amount of design development work carried out at the tender stage. These range from 'pure, or traditional, design and build' where the contractor is fully responsible for design and construction to 'develop and construct' where the client employs a design consultant for the scheme design and then the contractor completes the detailed design and constructs the work. 
Novation can offer the advantages of encouraging buildability and constructability (Griffith and Sidwell, 1995; 1997, CIIA, 1996). Contractors and architects have traditionally held different views over the benefits of novation. Akintoye's 1994 work found that novation is not widely favoured by contractors, principally because it assigns responsibility without custody of the project. Interestingly, Akintoye's later work with Fitzgerald (1995) shows that $52 \%$ of architects favour novation and they believe its popularity is linked to the clients' preference for it. This finding is not hard to understand when one considers that architects benefit from an increased revenue stream with novation. It could be inferred that the clients decision to adopt novation is being promoted by architects.

A wider study by Bennett et al. (1996) reported that 'the worst outcome, in meeting customers' quality requirements results from design-build approaches where novation is used'. Their report argues that fundamental conflict stems from the change in priorities part way through the design process in addition to the issue of where loyalties lie; in relation to either the contractor or client? Novation agreements typically state that following novation the architect's loyalties lie with the new employer; the contractor. Much literature raises the issue of conflict that stems from split loyalties, and it is the client's belief that there will be a residue of loyalty that often underlines their decision to adopt novation. However, Hackett (1998) shares similar sentiments to Minogue (1993) in that novation dismisses the client's belief in the designer's loyalty post-novation. Swindall (1993) states that the client's belief that the designer will still work in his favour can lead to the client suing the designer when the architect does not complete a particular duty at the post-novation stage.

The popularity of novation, both in the UK and worldwide, is strong. The report by Bennett et al. (1996) found that $37 \%$ of the 500 client respondents to their survey used novation. Further, they found that it was the fastest growing form of design and build and estimated that it accounted for $50 \%$ of all design and build work in 1996. These findings show that, despite its poor performance in relation to standards of quality and potential for conflict of interest, its rise in popularity seems unabated, reflecting the considerable need to understand more fully the dynamics of this procurement approach.

\section{RESEARCH DESIGN AND METHODOLOGY}

\section{Focus}

This study focuses on understanding the dynamics of novation from both the contractor's and architect's perspectives. The research is particularly pertinent given that the findings from previous research suggest that the characteristics of novation in practice remain unclear. The research presented in this paper forms one sub-set of a major UK government research project investigating design and build best practice (Griffith et al., 2003)

\section{Aim}

The aim of this paper is to better understand the dynamics of design and build novation from the experiences of practitioners. The identification and examination of the central themes, considerations and issues which arise at the different stages in the design and build procurement process will achieve this aim.

\section{Objectives}

- To examine the central themes, considerations and issues related to principal contractors involved in design-build novation.

- To examine the central themes, considerations and issues related to architects involved in design-build novation.

\section{Methodology}

The research uses a triangulated methodology with a mixture of qualitative and quantitative approaches. More specifically, a grounded theory methodology has been adopted for its ability to allow themes to emerge from the data without relying on a prior theory (Glaser and Strauss, 1967; Strauss and Corbin, 1998). The rationale for adopting a grounded theory methodology is linked to the gap in literature, lack of recognised theory and sometimes conflicting research surrounding the effects of novation on design and build procurement. Data collection methods included a series of semi-structured interviews, case studies and a nationwide-based questionnaire.

\section{Methods}

Semi-structured interviews were undertaken with 25 principal contractors and ten architects sampled from a range of companies of varying sizes and geographic locations within the UK. All respondents were regularly involved with and experienced in novated design and build. Questioning focused on identifying and explaining key aspects and issues from their experiences of working with such contracts. The interview data was indexed and analysed using 'Qualitative Solutions and Research (QSR) Non Numerical Unstructured Data Indexing Searching and Theorising (NUD*IST 5)' software in addition to 'Banxia Decision Explorer' software. The analysis followed a predetermined structured path resulting in categories of answers around aspects, issues and concerns. This level of precision in data modelling resulted in a highly refined database open to repeat and varied interrogation.

The structured questionnaire survey was developed from the findings of the interview element of the research design. The decision was taken to develop two discrete questionnaires to target contractors and consultants. This allowed the questions to be refined relevant to the individual strata. This stratified random sampling incorporated a sample size of 440 sourced from the 'Emap Glenigan national construction database' of UK planning applications and specifically aimed at those involved in 
design and build projects. The stratum consisted of an equal split of 220 contractors and consultants, respectively. The response rate from the survey was $20 \%$ with approximately equal response rates from each group and with wide geographic spread throughout the UK. This served to augment the interview data and to broaden the perspective of the total data through a greater number of primary data respondents. The questionnaire was developed using Teleform (version 7.0) software package and was analysed using Statistical Package for Social Sciences (SPSS, version 10).

\section{FINDINGS}

Underpinning objectives one and two of this paper, the central themes, considerations and issues that emerged from the data are presented on a theme by theme basis. A mixture of quantitative and qualitative data is used in the findings. An important advantage of the data-structuring approach is that it allows detailed qualitative data to be included in the findings. The key themes that emerged during analysis can be summarised as follows.

- Popularity of novated design and build-Novated design and build is being used on an increasing number of projects. Contractors and consultants reported that they encounter novation on $49 \%$ of their construction projects.

- The effects of dual loyalties on Architects' post-contract design and communication routes-Contractors find that architects still act as though they work for the client after novation, which causes various problems, such as over specifying elements.

- Working at risk-A majority of designers in the survey were increasingly working on a no-scheme-no-fee basis for mainly developer clients. These relationships force pressure on architects' finances and lead to information quality and delay issues.

- Unrealistic time pressures for the architectAll respondent architects in the survey reported that they become familiar with a project at the pre-novation phase, although this may only be represented in very loose drawings. Contractors often require very quick production of construction information, owing to the architects' familiarity, which leads to time pressures for the architect, and the potential for poor decision making.

- Drip-feeding of tender information-Two-thirds of contractors in the survey reported that they suffer serious information delays from the pre-novation architect at the tender stage. The tender stage is already short and these extra time pressures decrease the time available to contractors for risk assessment.

- Risk and value engineering - It was reported by over half of the contractors that novation reduces value-engineering exercises as it creates a potential forum for the dissemination of contractors competitive advantage. In addition, a contractor's inexperience with novated design results in higher risk sums having to be included in the tender.
- Effect on contractor selection and team relationshipsSeveral of the contractors reported that In extreme cases, contractors who have a history of poor payment to consultants can be deselected from the tender competition. In less extreme cases, such previous practice can sour team relationships between designer and contractor from the start of the project.

- Novation benefits-Although unrealistic time pressure is seen as a disadvantage by designers, it is also seen as an advantage by contractors, so fuelling the problem. Timescale issues apart, several contractors perceived the learning curve of the designers' previous experience as an advantage to the project. Almost all architects generally regarded novation as beneficial, a finding perhaps rooted in their increased revenue streams.

\section{The effects of dual loyalties on Architects' post-contract design and communication routes}

Contractors believe that some architects have the distinct problem of understanding that they do not work for the client at the post-contract stage once novation has taken place. Contractors have to make great efforts to educate architects that they now work for the contractor at the post-novation stage. Contractors report that architects still want to communicate directly with the client, and contractors have to reinforce that all communication should travel through them without being short circuited. The restrictions on this type of novation-shortcircuiting that are commented on by Siddiqui (1996) and Mosey (1998) are being breached.

Eighty-nine percent of contractors and consultants surveyed believed that the architect still had allegiance to the client at the post-contract stage, with $65 \%$ stating that this led to problems. Comparing consultants and contractors views regarding the architect's allegiance to the client at the post novation stage shows that there was no significant difference between the two samples. A particularly illuminating finding considering that the consultant stratum itself comprises architects.

The fact that architects are still liaising with the client and developing designs not tendered for may raise the client's expectations. When these expectations are not met, the client's satisfaction from the project may be artificially reduced. As illustrated in the literature, conflicts of interest are closely associated with novation. However, the data in the study shows that the architect's loyalties are complicated by the need to secure future work. Indeed, as discussed subsequently, developers tie this relationship into architects working at risk. Architects are worried that if they allow the contractor to compromise the pre-contract design, the client will not provide them with future work. The potential magnitude of this problem is clear when one considers the high amount of work secured on a repeat basis by architects. Commonly referred to as 'the two masters concept', the architect can be seen as being pulled by the irreconcilable forces of supply and demand. Whilst 
contractors generally agree that architects are expected by clients to continue to have allegiance to them, architects refute this type of practice after novation.

The conflict of interest issue is generally perceived to centre on the architect's response to the contractor's wish to change the design at the post-contract stage. However, architects contend that contractors do not wish to make many changes in today's industry, possibly mirroring a new maturity amongst contractors, or simply a result of the adoption of more developed forms of design and build.

\section{Working at risk}

Clients, who are typically developers, sometimes make deals with designers to produce pre-contact information without charge on the basis that if the project goes ahead then the designer will automatically be novated to the contractor. Some, although not all developers, offer enhanced fees should a project go ahead. Contractors believe that a designer working at risk can create serious problems in the construction process, specifically during the tendering element. First, tender drawings are of poor quality and are ultimately compromised. Second, designers can be so desperate for funds that they have been known to invoice contractors whilst they are still in contractor-selection negotiations, which negatively impacts on team building and group dynamics from the start of the project. Third, when novation has taken place, and designers have begun work on the project, they are still working at risk for developers on other projects that may or may not go ahead, thus diluting their resource base and leading to poor service provision for the contractor on the current project. Typical examples of reduced quality, highlighted by respondents, are drawings that need many revisions; late information and a lack of team playing.

On one particular project, the contractor deemed the pre-novation work of the structural engineer as inadequate when producing tender information. The contractor employed his own engineer and allowed him to price the project. As the original information from the first engineer was lacking on both time and quality criteria, the contractor included a recommendation to substitute the original designer for his own in his list of novation alternatives. In this instance, the designer working at risk led to higher tendering costs for the contractor.

Similar to contractors, architects do not view working at risk favourably, yet it is perceived as a necessary evil of today's construction environment. The pressure on architect's finances from working at risk has been commented on previously by Hayes (1987), yet this research study finds more wide ranging and problematic effects of its use.

\section{Unrealistic time pressures for the architect}

The pre-contract design stage allows architects to become familiar with the project. However, depending on the extent of pre-contract design, the drawings may still only be loosely developed when the contractor is selected. Contractors who novate architects often require hasty development of the construction drawings to allow them to make a start on site, itself one of the principal advantages of design and build. Contractors believe that the novated designers will be able to satisfy this need quickly owing to their knowledge of the project. Indeed, as reported later, contractors deem this an advantage of novation. However, architects find these demands unrealistic, especially where the design has only been developed to an early stage. Typically they have to comply with these demands irrespective of how unrealistic they are; a factor which architects believe can lead to bad decision-making. Paradoxically, contractors perception of a time advantage in the case of novation leads to more general problems, underlining the need to understand the dynamics of novation prior to usage.

\section{Drip-feeding of tender information}

Contractors suffer serious information delays and quality problems at the tender stage when novation is being used. These problems and delays have multiple sources, which complicate preventative measures.

\section{Contractors suffer from being drip fed information by} architects at the tender stage. This slow and interrupted information delivery makes it increasingly hard for contractors to produce tenders that have sufficiently explored risk issues in the tender time available. One respondent held the view that novated designers cannot provide good information at the tender stage as they have to deal with the requests from various tendering contractors. Contractors prefer to use their own architects as they get to know the design in more detail this way.

A belief shared throughout the data was that the dripfeeding of information at the tender stage can be isolated to the number of contractors making requests. However, this view was ruled out by another contractor who attributes it to the quality of the individual architect, the amount of pre-contract design work, and whether the architect is working at risk. With novation, the contractor believes that the pre-contract design should be developed further to allow more information to be available at the tender stage. This is an interesting finding as the general contractor's view of design and build is that the design should be developed to a minimal stage prior to contractor involvement.

\section{Risk and value engineering}

Novation affects tendering in numerous ways. In addition to the drip-feeding of information, novation negatively impacts on value engineering exercises and is considered a risk element by contractors who do not have experience of the novated architect.

Gaining maximum value from the construction process involves much more than simply securing the lowest cost during the tendering process. The value that the contractor can add to the project can be measured over a range of 
different attributes. Pro-active contractors are increasingly being schooled in the practice of value management and value engineering and apply these principles in their tender submissions. Value orientated initiatives rely on open dialogue between designer, client and contractor. In novated design and build all tendering contractors interact with the pre-novation designer, and it is the potential for the designer to diffuse the contractor's competitive advantage to others that inhibits value engineering exercises. The study findings confirm the comments made by Hackett (1998) mentioned previously.

The survey data shows that $69 \%$ of contractors seldom or never use their own architect on novated schemes, thus highlighting the loss of value-orientated activities that can typically be derived from contractors input. In addition to inhibiting value-engineering exercises, novation affects contractors risk calculations. The identification and allocation of risk at the tender stage is one of the key processes for the contractor to conduct. As discussed previously, the dripfeeding of information by designers complicates this process and reduces the already limited time available. However, novation impacts on risk in a much more direct way where the contractor does not have experience of the novated designer. Put simply, where the contractor has not worked with the designer before, they treat them as a risk element and price them accordingly. In this way novation can increase the tender price and the general costs to the industry.

\section{Affect on contractor selection and team relationships}

Novation can, in certain circumstances, affect contractor selection. Where a particular contractor has a reputation for not paying novated architects, it makes the architect reticent to be novated. In certain scenarios where the architect has a strong relationship with the client, and the price differential is low between contractor's bids, the architect's wishes can lead to the exclusion of those contractors who refuse to pay on time the agreed amounts. Even if the results are not as drastic as to affect contractor selection, they can seriously affect the team relationships, so important in an integrated construction route. It should be noted that the exclusion of certain contractors does not typically take place in an efficient manner as the contractor will have already committed his resources to and produced a tender before possible exclusion decisions are taken.

\section{Novation benefits}

The preceding discussion has generally highlighted the potential problems of novation and, as such, has presented the concept in a negative light. However, Novation does have certain positive facets, although these can be far from straightforward.

Contractors perceive novation to be advantageous as it reduces the timescale needed for designers to familiarise themselves with the project and produce construction drawings. This aspect is only viewed as advantageous by contractors, and simultaneously is considered a negative aspect by designers as they are typically not given enough time to produce the drawings.

Irrespective of the timescale benefits of prior project knowledge, contractors also deem the general learning curve that architects have gone through with a project at the pre-contract stage as advantageous. They regard this as important in understanding the finer details of the project, in addition to representing a good guide to understanding the clients needs. This is increasingly important where more developed forms of design and build are used, which do not allow them the close access that would have been case with more traditional design and build.

Architects regard design and build as generally positive, although the expectation of a duality of loyalties does cause problems. However, their general positive feelings are easily understandable when one considers that it guarantees them a revenue stream for the major part of the scheme.

However, it is not unknown for novated designers to be reduced to a minor role at post-contract stage if their novation agreement does not contain provisions to stop this. This state of affairs can arise as the contractor can rely heavily on both specialist subcontractors and in-house design staff to provide design details.

\section{CONCLUSIONS}

Novation seriously impacts on the tender process in various ways. The drip-feeding of information places increased pressures on contractors to assess the risk and understand the finer points of the project in already very limited tender periods. Where the poor information provided by prenovation architects necessitates the contractor employing his own designer, it amplifies the problem as it increases contractors tendering costs. In addition, novation reduces the dialogue between the contractor and the designer at the tender stage, reducing value-engineering exercises that are core to modern procurement. Novation goes further in affecting tendering issues, directly increasing risk allocations where contractors do not have experience of the novated designer.

The benefits of the learning curve that novation allows are indeed important, and can be seen as closely linked to the integrated fluid nature of design and build. However, the continuity that is afforded by keeping the same architect is far from simple. As the designer's loyalties change during the project, the fluidity of the project can be compromised. One way to alleviate this is to develop the design further prior to the tender stage, this having the affect of tying the contractor into a more established and precise design. However, this in itself detracts from the singular party ethos of design and build, and reduces the impact of the contractor who is well positioned to offer valuable input. 


\section{REFERENCES}

Akintoye, A. (1994). Design and build: a survey of construction contractor's views. Construction Management and Economics, 12, 155-163.

Akintoye, A. and Fitzgerald, E. (1995). Design and build: a survey of architect's views. Engineering, Construction and Architectural Management, 2(1), 27-44.

Andrews, S. (1999). Update on Design and Build. Architects' Journal, 3 June.

Ministry of Public Buildings and Works (1964). The Placing and Management of Contracts for Building and Civil Engineering Work, (Banwell Report). HMSO, London.

Bennett, J., Pothecary, E. and Robinson, G. (1996). Designing and Building a World-Class Industry. Centre for Strategic Studies in Construction, University of Reading, Reading.

Chappell, D. (1994). Architects' legal position on D\&B. Special Report Design and Build. Architects' Journal. 9 March.

Chevin, D. (1993). Fitting The Bill. Design and Build Supplement, Building, 30 July.

Construction Industry Institute, Australia, (CIIA) (1996). Constructability Manual. CIIA, Adelaide.

Glaser, B.G. and Strauss, A.L. (1967). The Discovery of Grounded Theory. Aldine, Chicago.

Griffith, A. and Sidwell, A.C. (1995). Constructability in Building and Engineering Projects. Macmillan, Basingstoke.

Griffith, A. and Sidwell, A.C. (1997). Development of Constructability Concepts, Principles and Practices. Engineering. Construction and Architectural Management, 4(4), 295-310.

Griffith, A., Knight, A. and King, A. (2003). Best Practice Tendering for Design and Build Projects. Thomas Telford, London.

Hackett, J. (1998). Design and Build: Uses and Abuses. LLP Reference Publishing, London.

Hayes, K. (1987). Design and Build here to stay! RIBA Practice. April.

Latham, M. (1994). Constructing the Team. Final Report of the joint government/industry review of procurement and contractual arrangements in the United Kingdom construction industry. HMSO, London.
Minogue, A. (1993). Setting up the Contract. Design and Build Supplement, Building. 30 July.

Mosey, D. (1998). Design and Build in Action. Chandos Publishing, Oxford.

Schuman, N. (1999). A Game of Two Halves. Building. 3 September.

Siddiqui, A.W. (1996). Novation: and its comparison with common forms of building procurement. Construction Papers, No. 60. The Chartered Institute of Building (CIOB), Ascot.

Strauss, A. and Corbin, J.M. (1998). Basic of Qualitative Research : Grounded Theory Procedures and Techniques. Sage, London.

Swindall, W. (1993). Understanding Novation. Design and Build Supplement, Building. 30 July.

Turner, A. (1990). Building Procurement. Macmillan, Basingstoke.

Turner, D.F. (1995). Design and Build Contract Practice. Longman, Harlow. 